\title{
Clinical Advantage of Propofol Compared with Barbiturate for the Coma Therapy in the Patients with Severe Traumatic Brain Injury
}

\author{
Hye Jin Shin ${ }^{1}$, Geun Young Yang ${ }^{1}$, Young Zoon Kim ${ }^{2}$ \\ ${ }^{1}$ Department of Anesthesiology and Pain Medicine, Samsung Changwon Hospital, Sungkyunkwan University School of Medicine, Changwon, Korea \\ ${ }^{2}$ Department of Neurosurgery, Samsung Changwon Hospital, Sungkyunkwan University School of Medicine, Changwon, Korea
}

Received: August 14, 2018

Accepted: September 19, 2018

Published: October 10, 2018

\section{Corresponding Author:}

Young Zoon Kim, M.D., Ph.D.

Department of Neurosurgery,

Samsung Changwon Hospital, Sungkyunkwan University School of Medicine, 158 Paryong-ro, Masanhoewon-gu, Changwon 51353, Korea

Tel: +82-55-233-5241

Fax: $+82-55-233-8040$

E-Mail: yzkim@skku.edu

\section{Objective}

Barbiturates have been demonstrated to reduce intracranial pressure (ICP), but adverse effects, which include hypotension and a long recovery time, make clinical applications difficult. Propofol is also known to have same effect. In the present study, we undertook coma therapy using propofol or barbiturate and compared clinical value in the practical point.

\section{Methods}

From June 2014 to April 2017, 38 patients with severe traumatic brain injury underwent thiopental or propofol coma therapy for the 3 days following neurosurgery. Seventeen patients were treated with thiopental (group A) and 21 patients with propofol (group B).

Results

Mean doses were $6.1 \mathrm{mg} / \mathrm{kg} / \mathrm{hr}$ of thiopental and $4.4 \mathrm{mg} / \mathrm{kg} / \mathrm{hr}$ of propofol. In group A, mean bispectral indexes were 29.4 on day $1,27.4$ on day 2 , and 26.0 on day 3 , and in group B, 31.4 on day $1,29.9$ on day 2 , and 27.8 on day 3 . Mean ICP was $16.8 \mathrm{~cm}$ on day $1,24.4 \mathrm{~cm}$ on day 2 and $15.1 \mathrm{~cm}$ on day 3 in group A, and $18.3 \mathrm{~cm}$ on day $1,25.4 \mathrm{~cm}$ on day 2 and $18.0 \mathrm{~cm}$ on day 3 in group B. To maintain systemic normotentsion, dopamine was infused continuously at mean doses of $10.2 \mu \mathrm{g} / \mathrm{kg} / \mathrm{min}$ in group A and $4.4 \mu \mathrm{g} / \mathrm{kg} / \mathrm{min}$ in group B. Mean times to stationary state were 32.9 hours in group $A$ and 6.6 hours in group $B$.

\section{Conclusion}

The present study suggest that propofol coma therapy has less systemic hypotension and shorter time to stationary state than thiopental therapy for achieving the same depth of anesthesia and ICP-reducing effect.

Keywords: Propofol; Barbiturate; Coma therapy; Bispectral index; Traumatic brain injury 


\section{INTRODUCTION}

The potential neuroprotective effects of barbiturates and propofol have been long recognized. These drugs induce a dosedependent reduction in the cerebral metabolic rate of oxygen $\left(\mathrm{CMRO}_{2}\right)$ until silence on electroencephalography (EEG), after which additional doses have no beneficial effects. ${ }^{12,18)}$ Furthermore, they can reduce cerebral blood flow $(\mathrm{CBF})$ in the non-ischemic brain by increasing vascular resistance and reduce intracranial pressure (ICP) ${ }^{1,11,12)}$.

Numerous theories have been proposed to explain the ability of barbiturates and propofol to prevent or treat cerebral ischemia. The most quoted major neuroprotective mechanism involves the dose-dependent diminution of $\mathrm{CMRO}_{2}$ (up to 50 percent) in human and animals until EEG silence. ${ }^{15,21)}$ Other potential mechanisms of neuroprotection include: stabilization of lysosomal membranes, the attenuation of intracellular calcium concentrations, anti-oxidative and anti-excitotoxic processes $^{19,22,23)}$.

The general brief is that maximal neuroprotection is achieved at doses producing silent $\mathrm{EEG}^{20,24)}$. However, higher doses can cause many complications in clinical practice. Moreover, smaller doses may be as efficacious as those required to obtain burst suppression. This is important when considering the deleterious side effects of barbiturates, because of: 1) cardiopulmonary dose-dependent depressant effects and the prolonged ventilation required in patients receiving burst-suppression doses, 2) the increased risk of infection attributable to barbiturates and the need for invasive monitoring, and 3) a depression of mental status that obscures neurological evaluations ${ }^{13)}$.

However, propofol has a shorter recovery time and induces less systemic hypotension than barbiturate ${ }^{2,12}$. Therefore, coma therapy using propofol might be more convenient and less complicated than therapies based on barbiturate. In an attempt to compare the clinical application of two drugs, such as depth of anesthesia, changes of ICP, methods to maintain systemic normotension, recovery time from coma therapy and their complications, we performed retrospective study of coma therapy after craniotomy or craniectomy for severe traumatic brain injury (TBI) using propofol or thiopental as general anesthetic agents in two patient groups.

\section{MATERIAL AND METHODS}

From June 2014 to April 2017, 38 patients underwent coma therapy after brain surgery for the severe TBI at our institute. Of these, 17 patients (group A) underwent coma therapy with thiopental (Pentotal Sodium ${ }^{\circledR}$ ) after brain surgery for the first
18 months (from June 2014 to November 2015), whereas, 21 patients (group B) underwent coma therapy with propofol (Fresofol $2 \%^{\circledR}$ ) during the next 17 months (from December 2015 to April 2017).

Based on preoperative consciousness of patients and intraoperative findings, the following conditions were considered before deciding to perform neuroprotective coma therapy: 1) in severe TBI patients with Glasgow Coma Scale (GCS) score $<9 ; 2$ ) in the case of that severe brain swelling and midline shifting may lead to cerebral herniation; 3 ) in the case of that discolarization of brain and weak or absent brain pulsation of the operative findings

\section{Monitoring of burst-suppression patterns by EEG}

After brain surgery, all the patients were transfer to a neurosurgical intensive care unit under a deep hypnotic state. The induction of coma therapy and anesthetic agent titration targeted the appearance of EEG burst-suppression patterns.

EEG signals were obtained using gold cup electrodes applied to the scalp with cream, and were located according to the international 10-20 systems. Skin impedance was maintained at $<5 \mathrm{~K} \Omega$. The following leads were recorded: left and right frontal-mastoid ( $\mathrm{F}_{\mathrm{P} 1}-\mathrm{A}_{1}, \mathrm{~F}_{\mathrm{P} 2}-\mathrm{A}_{2}$, channels 1 and 2$)$, left and right frontal- $\mathrm{C}_{\mathrm{Z}}\left(\mathrm{F}_{\mathrm{P} 1}-\mathrm{C}_{\mathrm{Z}}, \mathrm{F}_{\mathrm{P} 2}-\mathrm{C}_{\mathrm{Z}}\right.$, channels 3 and 4$)$, plus a ground electrode placed at the center of the forehead. EEGs were recorded using a portable Aspect A-1000 EEG monitor (Aspect Medical System, Inc., Natick, MA, USA).

\section{Setting of bispectral index (BISTM)}

After achieving a burst-suppression pattern on the portable EEG, we replaced electrodes for the BIS ${ }^{\mathrm{TM}}$ (BisSensor; Aspect Medical Systems, Inc., Newton, MA, USA) on the forehead, as specified by the manufacturer, and measured signals using an Aspect A-2000 EEG monitor (software version 3.3; Aspect Medical System, Inc., Newton, MA, USA). For polysomnography, we placed a midline frontoparietal electrode for EEG, an electrode at canthus and above unilateral eye for electro-oculography and a submental electrode for electromyography. BIS scores on the monitor were recorded at 2-hours interval using a monitor and data were collected. And then we compared the scores between two groups.

\section{Anesthetic procedures}

In group A, thiopental was administered in increments of 50-100 mg intravenously at 1- to 5-minutes intervals, and in group B, propofol was administered in increments of $10-20 \mathrm{mg}$ intravenous push at 5- to 10-minutes intervals in an attempt to achieve an EEG burst-suppression pattern. BIS scores were 
then recorded. Anesthetic doses were incrementally and slowly adjusted upward to achieve the desired endpoint, i.e., an EEG burst-suppression pattern, and BIS scores were then recorded.

After the induction of general anesthesia and loss of consciousness (no response to verbal commends, loss of eyelid reflex, and loss of self respiration), respiration was conducted using a mechanical ventilator with $30 \sim 40 \%$ oxygen via an endotracheal tube. No other neuromuscular blockers were used. After determining target BIS scores below 40 with silence on EEG, to maintain general anesthesia, patients in group A received thiopental and those in group $B$ propofol at doses of between the previously determined target BIS score +5 and -5 .

\section{Other monitoring during therapy}

Patient's anesthetic states were clinically monitored using the modified Observer Assessment of Alertness and Sedation (MOAAS) scale, i.e., when a patient responded readily to his/ her name spoken in normal tone a score of 5 was allocated; when a patient responded lethargically a score of 4 was allocated; when a patient responded only after calling in a loud voice or repeatedly a score of 3 was allocated; when a patient responded only after mild prodding or shaking a score of 2 was allocated; when a patient did not respond to mild prodding or shaking a score of 1 was allocated; and a score of 0 was allocated when a patient did not respond to a noxious stimulus.

ICP was monitored by use of epidural fiberoptic catheter and sensor that was placed in the space between dura and craniected muscle or scalp. Digitalized numbers on the ICP monitor were recorded every 2 hours. Vital signs were checked and recorded every hour. When systolic blood pressure fell below 100 $\mathrm{mmHg}$, a catecholamine (e.g., dopamine) was used to raise and maintain systolic blood pressure to at least $100 \mathrm{mmHg}$; doses administered were recorded.

\section{Recovery time from coma therapy to stationary state}

After the discontinuance of anesthetics, patient consciousness was checked every two hours using the MOAAS and GCS scores. Recovery time was calculated from the time of stopping anesthesia to the point when these scales indicated a neurologically stationary state, which was checked at least 12 times with 2-hours interval. When the patient recovers slowly after a day, the identical results in the 6 times sequential repeated tests was determined as stationary state. When a patient's vital signs, neurological signs, and respiration became stable, mechanical ventilation was stopped. No thiopental or propofol antagonists were administered. And then, the recovery time was compared between two groups.

\section{Statistical analysis}

The t-test, the Chi-square test and Fisher's exact test were used to compare the two groups in terms of baseline characteristics and each parameter for assessment. Results were considered significant when p-values were less than 0.05 . Statistical analyses were performed using SPSS version 20.0 (SPSS Institute, Inc, Chicago, IL)

\section{RESULTS}

\section{Characteristics of the patient populations}

Table 1 summarizes patient characteristics and initial diagnoses. There were 16 male and 22 female patients of mean age of 54.5 years (range: $33-68$ ) when coma therapy was performed. In group A, there were 10 men and 7 women of mean age 55.5 years (range: $37-68$ ), and in group B, there were 9 men and 12 women of mean age 53.7 years (range: $33-68$ ). Initial diagnoses were as follows; 16 acute subdural hemorrhages (7 in group A and 9 in group B), 10 traumatic intracerebral hemorrhage (4 in group A and 6 in group B), 5 diffuse cerebral hemorrhagic contusion ( 3 in group A and 2 in group B), 3 epidural hemorrhages ( 2 in group $A$ and 1 in group $B$ ), 3 diffuse cerebral edema with diffuse axonal injury ( 1 in group $A$ and 2 in group B), and 1 other disease. All the patients underwent craniotomy or craniectomy. The mean overall preoperative GCS score was 6.6 (6.4 in group A and 6.8 in group B) and ranged from 4 to 8 . No significant difference was observed between

Table 1. Clinical features of the patients at initial presentation*

\begin{tabular}{|c|c|c|c|c|}
\hline & & $\begin{array}{c}\text { Total } \\
(\mathbf{N}=\mathbf{3 8})\end{array}$ & $\begin{array}{l}\text { Group A } \\
(\mathbf{N}=\mathbf{1 7})\end{array}$ & $\begin{array}{l}\text { Group B } \\
(\mathbf{N}=\mathbf{2 1})\end{array}$ \\
\hline \multirow{2}{*}{ Gender } & Male & $16(42.1 \%)$ & $10(58.8 \%)$ & $9(42.9 \%)$ \\
\hline & Female & $22(57.9 \%)$ & $7(41.2 \%)$ & $12(57.1 \%)$ \\
\hline \multirow{4}{*}{ Age (years) } & Mean & 54.5 & 55.5 & 53.7 \\
\hline & Range & $(33-68)$ & $(37-68)$ & $(33-68)$ \\
\hline & $\begin{array}{l}\text { Acute } \\
\text { subdural } \\
\text { hematoma }\end{array}$ & $16(42.1 \%)$ & $7(41.2 \%)$ & $9(42.9 \%)$ \\
\hline & $\begin{array}{l}\text { Traumatic } \\
\text { intracerebral } \\
\text { hematoma }\end{array}$ & $10(26.3 \%)$ & $4(23.5 \%)$ & $6(28.6 \%)$ \\
\hline \multirow[t]{4}{*}{ Diagnosis } & $\begin{array}{l}\text { Hemorrhagic } \\
\text { contusion }\end{array}$ & $5(13.2 \%)$ & $3(17.6 \%)$ & $2(9.5 \%)$ \\
\hline & $\begin{array}{l}\text { Epidural } \\
\text { hematoma }\end{array}$ & $3(7.9 \%)$ & $2(11.8 \%)$ & $1(4.8 \%)$ \\
\hline & $\begin{array}{l}\text { Diffuse } \\
\text { cerebral } \\
\text { edema }\end{array}$ & $3(7.9 \%)$ & $1(5.9 \%)$ & $2(9.5 \%)$ \\
\hline & Others & $1(2.6 \%)$ & $0(0.0 \%)$ & $1(4.8 \%)$ \\
\hline \multirow{2}{*}{$\begin{array}{l}\text { Initial } \\
\text { GCS score }\end{array}$} & Mean & 6.6 & 6.4 & 6.8 \\
\hline & Range & $(4-8)$ & $(4-8)$ & $(4-8)$ \\
\hline
\end{tabular}


two groups in terms of demographic parameters, diseases, or preoperative GCS scores.

\section{BIS scores}

After achieving a burst-suppression pattern on EEG, BIS scores were recorded every 2 hours for 3 days during coma therapy, and average values were calculated (Table 2). For all patients, mean BIS scores were; 29.4 on the first day, 27.4 on the second day, and 26.0 on the last day. In group A, mean BIS scores were 26.9 on the first day, 24.3 on the second day, and 23.7 on the last day. In group B, mean BIS scores were 31.4 on the first day, 29.9 on the second day, and 27.8 on the last day. The two groups had no differences in terms of BIS scores.

\section{MOAAS scores}

Hypnotic depth was checked by physicians, and MOAAS scores were recorded every 2 hours during coma therapy (Table 2). For all patients, mean MOAAS scores were 0.66 on the first day, 0.61 on the second day and 0.39 on the last day. In group A, mean MOAAS scores were 0.24 on the first day, 0.17 on the second day and 0.00 on the last day. In group B, mean MOAAS scores were 1.00 on the first day, 0.95 on the second day, and 0.71 on the last day. In terms of MOAAS scores, no significant differences were found between the two groups and all the patients were well controlled under deep anesthesia.

\section{Results of ICP monitoring}

In the first day of coma therapy, mean ICP for all the patients was $17.5 \mathrm{cmH}_{2} \mathrm{O}$ and $16.8 \mathrm{cmH}_{2} \mathrm{O}$ in group $\mathrm{A}$ and $18.3 \mathrm{cmH}_{2} \mathrm{O}$ in group $\mathrm{B}$, respectively. In the second day, mean ICP for all the patients was increased to $24.9 \mathrm{cmH}_{2} \mathrm{O}$ and $24.4 \mathrm{cmH}_{2} \mathrm{O}$ in group $\mathrm{A}$ and $25.4 \mathrm{cmH}_{2} \mathrm{O}$ in group $\mathrm{B}$. In the last day, mean ICP for all the patients was decreased again to $16.6 \mathrm{cmH}_{2} \mathrm{O}$ and 15.1 $\mathrm{cmH}_{2} \mathrm{O}$ in group $\mathrm{A}$ and $18.0 \mathrm{cmH}_{2} \mathrm{O}$ in group $\mathrm{B}$, respectively. No statistical difference was found between two groups in the ICP (Table 2).

\section{Dose of anesthetics and cardiotonics}

In group $\mathrm{A}$, the mean dose of thiopental administered was 6.1 $\mathrm{mg} / \mathrm{kg} / \mathrm{hr}$ (range: $4.5-7.5 \mathrm{mg} / \mathrm{kg} / \mathrm{hr}$ ) and in group B, the mean dose of propofol administered was $4.4 \mathrm{mg} / \mathrm{kg} / \mathrm{hr}$ (range: $3.5-6.0$ $\mathrm{mg} / \mathrm{kg} / \mathrm{hr}$ ).

To maintain systemic normotensive state, dopamine was administered to counter cardiac depression due to anesthetics. Except for dopamine, no other agent was administered to increase systemic pressure. The mean overall dose of dopamine administered was $7.0 \mu \mathrm{g} / \mathrm{kg} / \mathrm{min}$ (range: $0.0-14.0 \mu \mathrm{g} / \mathrm{kg} / \mathrm{min}$ ). In group $\mathrm{A}$, the mean dose of dopamine was $10.2 \mu \mathrm{g} / \mathrm{kg} / \mathrm{min}$ (range: $8.0-14.0 \mu \mathrm{g} / \mathrm{kg} / \mathrm{min}$ ) and in group B, $4.4 \mu \mathrm{g} / \mathrm{kg} / \mathrm{min}$ (range: $0.0-8.0 \mu \mathrm{g} / \mathrm{kg} / \mathrm{min}$ ). Significantly less dopamine was administered to maintain systemic pressure in group B than in group $A(p=0.000)$ (Table 2$)$.

\section{Recovery from anesthesia to the stationary state}

The mean overall recovery time was 18.4 hours (range: 4.048.0 hours) and summarized on table 2 . In group A, it was 32.9 hours (range: $20.0-48.0$ hours) and in group B, 6.6 hours (range: 4.0-10.0 hours). It took shorter time to recover from anesthesia for patients who were treated with propofol than those who were treated with barbiturate $(\mathrm{p}=0.000)$.

Table 2. Clinical features during coma therapy*

\begin{tabular}{|c|c|c|c|c|c|}
\hline & & Total $(\mathbf{N}=38)$ & Group $A(N=17)$ & Group B $(N=21)$ & p-value ${ }^{\dagger}$ \\
\hline \multirow[t]{2}{*}{ Mean dose of anesthetics (mg/kg/hr) } & & & $6.1(4.5-7.5)$ & $4.4(3.5-6.0)$ & \\
\hline & Day 1 & $29.4(21.5-40.1)$ & $26.9(21.5-33.5)$ & $31.4(25.4-40.1)$ & 0.752 \\
\hline \multirow[t]{3}{*}{ Mean bispectral Index } & Day 2 & $27.4(19.3-35.6)$ & $24.3(19.3-27.2)$ & $29.9(22.6-35.6)$ & 0.691 \\
\hline & Day 3 & $26.0(20.7-37.0)$ & $23.7(20.7-30.2)$ & $27.8(21.0-37.0)$ & 0.721 \\
\hline & Day 1 & $0.66(0.0-1.0)$ & $0.24(0.0-1.0)$ & $1.00(1.0-1.0)$ & 0.882 \\
\hline \multirow[t]{3}{*}{ Mean MOAAS Score } & Day 2 & $0.61(0.0-1.0)$ & $0.17(0.0-1.0)$ & $0.95(0.0-1.0)$ & 0.902 \\
\hline & Day 3 & $0.39(0.0-1.0)$ & $0.00(0.0-0.0)$ & $0.71(0.0-1.0)$ & 0.880 \\
\hline & Day 1 & $17.5(11.6-28.6)$ & $16.8(11.6-24.0)$ & $18.3(14.0-28.6)$ & 0.639 \\
\hline \multirow[t]{2}{*}{ Intracranial pressure $\left(\mathrm{cmH}_{2} \mathrm{O}\right)$} & Day 2 & $24.9(13.6-35.4)$ & $24.4(13.6-33.5)$ & $25.4(17.3-35.4)$ & 0.756 \\
\hline & Day 3 & $16.6(11.0-22.4)$ & $15.1(11.0-22.0)$ & $18.0(12.0-22.4)$ & 0.108 \\
\hline \multirow{2}{*}{ Dose of dopamine $(\mu \mathrm{g} / \mathrm{kg} / \mathrm{min})$} & Mean & 7.0 & 10.2 & 4.4 & $<0.001$ \\
\hline & Range & $(0.0-14.0)$ & $(8.0-14.0)$ & $(0.0-8.0)$ & \\
\hline \multirow{2}{*}{ Recovery time (hour) } & Mean & 18.4 & 32.9 & 6.6 & $<0.001$ \\
\hline & Range & $(4.0-48.0)$ & $(20.0-48.0)$ & $(4.0-10.0)$ & \\
\hline
\end{tabular}

* MOAAS : Modified Observer Assessment of Alertness and Sedation.

${ }^{+}$t-test. 


\section{Outcome}

GCS score after stationary condition from coma therapy was not significantly different before coma therapy. The mean overall post-therapeutic GCS score was 6.8 (6.7 in group A and 7.0 in group B) and ranged from 3 to 10 . Four patients (23.5\%) in group A got worse than before and 4 patients (19.0\%) in group B did. Seven patients (41.2\%) in group A improved and 11 patients (52.4\%) in group B did. However, the difference between two groups did not have statistical significance $(\mathrm{p}=0.352)$.

\section{Complications of coma therapy}

Table 3 presents the complications that occurred during coma therapy. No patient died during therapy. Although all patients experienced side effects to some degree, their complications were minimal and not life-threatening, i.e., systemic hypotension (systolic blood pressure $<100 \mathrm{mmHg}$ ) occurred in 35 patients (17 in group A and 18 in group B), electrolyte imbalances (hyponatremia, hypokalemia, or hypercalcemia) occurred in 10 patients (4 in group A and 6 in group B), leukocytosis $(>10,000 / \mu \mathrm{L})$ occurred in 7 patients ( 4 in group $A$ and 3 in group $B)$, appearance of pneumonic consolidation on chest $\mathrm{X}$-ray occurred in 6 patients ( 3 in group A and 3 in group B), increased erythrocyte sedimentation rate (ESR) $(>20 \mathrm{~mm} /$ $\mathrm{hr})$ or C-reactive protein $(\mathrm{CRP})(>5 \mathrm{mg} / \mathrm{L})$ in 5 patients $(3$ in group $\mathrm{A}$ and 2 in group $\mathrm{B})$, increased serum blood urea nitrogen $(\mathrm{BUN})(>25 \mathrm{mg} / \mathrm{dL})$ or creatinine $(>1.5 \mathrm{mg} / \mathrm{dL})$ in 4 patients ( 1 in group A and 3 in group B), acidosis in 4 patients ( 2 in group $A$ and 2 in group $B$ ), arrhythmia by electrocardiography (ECG) in 3 patients ( 2 in group $A$ and 1 in group B), increased lactate dehydrogenase $\mathrm{H}(\mathrm{LDH})$ in 2 patients ( 0 in group $A$ and 2 in group B) and deep vein thrombosis in 2 patients ( 1 in group $\mathrm{A}$ and 1 in group $\mathrm{B})$. No fever $\left(>38.0^{\circ} \mathrm{C}\right)$ was found in any patient. There was no statistical difference in complication between two groups.

\section{Illustration of case}

A 64-year-old woman visited emergent care unit with acute alteration of mentality after head trauma from fall-down. Her pupils did not response to the light and she had decorticated movement to noxious stimulation. GCS score was 6 . On the computed tomographic (CT) scan, crescent-shaped, highdensity lesion on the left fronto-temporal area was found. And midline was shifted to the right side and sulci were obliterated. Under impression of acute subdural hemorrhage, she underwent decompressive craniectomy and subdural hemorrhage was removed. In the neurosurgical field, the brain was tense and swelling up severely and decreased brain pulsation and discoloration was found. After brain surgery, we started coma therapy using propofol with a dose of $4 \mathrm{mg} /$ $\mathrm{kg} / \mathrm{hr}$ to reduce intracranial pressure and lessen the brain damage. Initially, the dose was titrated by use of portable EEG monitoring with confirmation of burst-suppression pattern and then was maintained with a dose of $6 \mathrm{mg} / \mathrm{kg} / \mathrm{hr}$. BIS score was ranged from 35 to 50 during coma therapy. Dopamine with a dose of $4 \mu \mathrm{g} / \mathrm{kg} / \mathrm{min}$ was administrated to maintain normotensive systemic pressure. During coma therapy, she experienced increase of serum $\mathrm{LDH}(315 \mathrm{IU} / \mathrm{mL})$, leukocytosis $(15,000 / \mu \mathrm{L})$ and metabolic acidosis (serum $\mathrm{pH} 7.30)$. She recovered from coma therapy 6 hours to stationary state after discontinuance of propofol administration. Fortunately, she improved minimally with withdraw movement to pain and pupillary response to the light returned. But she was unable to cooperate with physician and GCS score was 8 . Fig. 1 shows pre- and immediate postoperative imaging scan, EEG finding and BIS setting.

Table 3. Complications of neuroprotective coma therapy*

\begin{tabular}{|c|c|c|c|c|}
\hline & Total $(\mathrm{N}=38)$ & Group $A(N=17)$ & Group B $(N=21)$ & p-value ${ }^{+}$ \\
\hline Hypotension $(\mathrm{SBP}<100 \mathrm{mmHg})$ & $35(92.1 \%)$ & $17(100 \%)$ & $18(85.7 \%)$ & 0.752 \\
\hline Electrolyte imbalance & $10(26.3 \%)$ & $4(23.5 \%)$ & $6((28.6 \%)$ & 0.911 \\
\hline Leukocytosis $(>10,000 / \mu \mathrm{L})$ & $7(18.4 \%)$ & $4(23.5 \%)$ & $3(14.3 \%)$ & 0.535 \\
\hline Pneumonic consolidation & $6(15.8 \%)$ & $3(17.6 \%)$ & $3(14.3 \%)$ & 0.902 \\
\hline Increase of ESR or CRP & $5(13.2 \%)$ & $3(17.6 \%)$ & $2(9.5 \%)$ & 0.887 \\
\hline Increase of BUN/Cr & $4(10.5 \%)$ & $1(5.9 \%)$ & $3(14.3 \%)$ & 0.135 \\
\hline Acidosis & $4(10.5 \%$ & $2(11.8 \%)$ & $2(9.5 \%)$ & 0.826 \\
\hline Arrhythmia & $3(7.9 \%)$ & $2(11.8 \%)$ & $1(4.8 \%)$ & 0.604 \\
\hline Increase of LDH & $2(5.3 \%)$ & $0(0.0 \%)$ & $2(9.5 \%)$ & 0.078 \\
\hline Deep vein thrombosis & $2(5.3 \%)$ & $1(5.9 \%)$ & $1(4.8 \%)$ & 0.921 \\
\hline
\end{tabular}

*ESR : erythrocyte sedimentation rate; CRP : C-reactive protein; BUN : blood urea nitrogen; $\mathrm{Cr}$ : creatine; LDH : lactate dehydrogenase H.

${ }^{+}$Fisher's exact test. 


\section{DISCUSSION}

In this study, we found that propofol coma therapy has a shorter recovery time from general anesthesia, induces less systemic hypotension, and requires less dopamine than
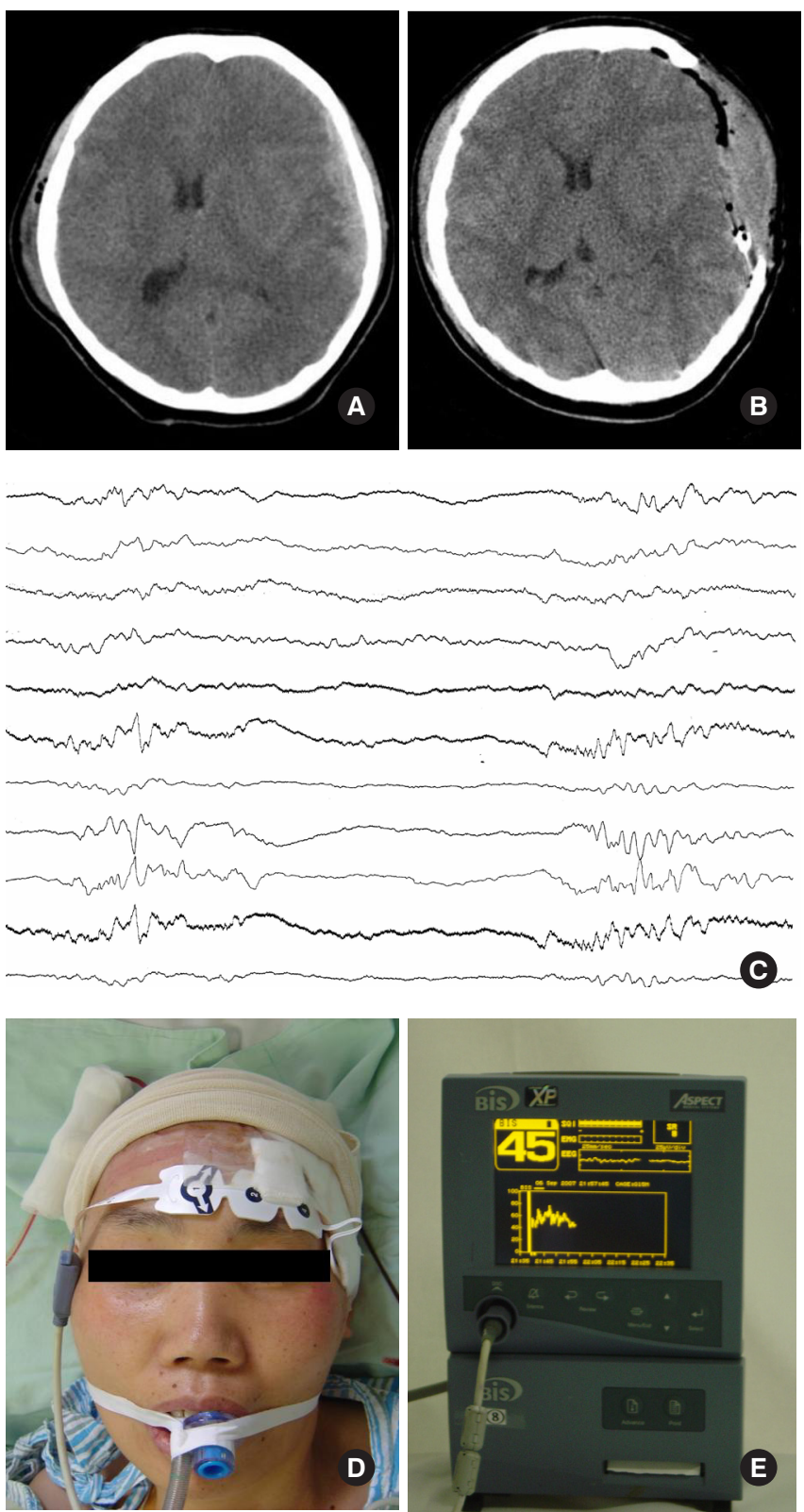

Fig. 1. A 64-year-old woman visited emergency care unit with acute altered mentality after head trauma. A: At admission, precontrast computed tomographic (CT) image showed crescent-formed, high-density lesion on the left fronto-temporal area and midline shift to right side. B: After craniectomy and removal of hemorrhage, there was aggravated midline shift on the immediate postoperative CT scan. C: In order to titrate propofol dosage, burst-suppression pattern was confirmed by use of the portable EEG monitoring. D: BIS leads were placed on her forehead. E: BIS monitoring was started after titration of propofol dose. thiopental coma therapy. However, no difference was observed between the propofol and thiopental groups in terms of BIS scores, MOAAS scores, changes in ICP, outcome, and side effects.

In general, propofol has similar neuroprotective effects as barbiturate, but also has several advantages ${ }^{18)}$. First, propofol has a shorter half time and recovery time from anesthesia than barbiturate, which can facilitate early neurological evaluation. Second, the lower systemic hypotension associated with propofol can reduce catecholamine requirements. Third, some authors have suggested that the risk of infection may be lower for propofol than barbiturate. Finally, propofol provides an energy source due to its lipid content. With coincidence, in presenting study, patients who underwent propofol coma therapy had shorter recovery time and lower systemic hypotension and less catecholamine requirement. But, in terms of infection, there was no difference between two groups. Hatch DJ suggested that propofol coma therapy for $>2$ days has much higher risk of infection ${ }^{7}$. In this study of 3 day-schedule coma therapy, as many as six patients gained pneumonic consolidation on chest $\mathrm{X}$-ray without fever.

However, despite the practical advantages of propofol, it is not completely safe, especially when administered at high doses, because at high levels propofol accentuates lactate accumulation and edema formation in cases of cerebral ischemia with hyperglycemia ${ }^{8)}$. Moreover, propofol infusion syndrome is a rare but often fatal syndrome that was originally described in critically ill children undergoing long-term ( $>48$ hours) propofol infusion at high doses $(>4 \mathrm{mg} / \mathrm{kg} / \mathrm{hr})^{7)}$. Its features consist of severe metabolic acidosis, rhabdomyolysis, renal failure, and fatal cardiac failure. Moreover, this pathologic condition can be aggravated by the combined use of glucocorticoid and catecholamine. In combination with glucocorticoid, high dose of propofol can exert profound effects on immunity and inflammation ${ }^{3)}$. In combination with catecholamine, the negative inotropic effects of propofol can increase catecholamine requirement, and thus, create a vicious cycle that results in a progressive myocardial depressive effect ${ }^{3}$. For these reasons, high-dose propofol for prolonged period ( $>48$ hours) is not recommended ${ }^{5,9}$. Therefore, determination of optimal barbiturate and propofol concentration is of considerable importance.

In this point of view, BIS scores can titrate the optimal dose of barbiturate and propofol until burst-suppression pattern appear on the EEG. In fact, BIS scores were developed to measure the effects of anesthetic agents on the brain ${ }^{10)}$. Over several years, a large database of high fidelity EEG recordings and clinical recordings from more than 2,000 patients that 
received a wide variety of anesthetic regimens, were collected by Aspect Medical Systems, Inc. This database contains recorded EEG segments and records of associated clinically derived hypnotic states. According to this setting, BIS score of 65-85 have been recommended for sedation, score of 40-65 have been recommended for general anesthesia, and at the score of lower than 40, cortical suppression becomes discernible in EEG as a burst suppression pattern. Almost patients in this study had the BIS score of lower 40 during coma therapy. Therefore, BIS scores can be used to manage anesthetics effectively and reduce drug usage, reduce recovery time, facilitate higher quality recovery, and reduce the side effects of prolonged anesthesia ${ }^{4)}$.

In presenting study, we monitored ICP with epidural catheter and sensor and performed coma therapy during continuous 3 days. However, according to guideline by Martin R. et al., severe TBI patients were recommended to monitor ICP with ventricular catheter ${ }^{14)}$. Although true ICP shows a potential to warn against the elevation of ICP, continuous analysis of intracranial pressure adds information to simple recording of mean trend values actually ${ }^{6}$. In fact, there are no strict and absolute guideline for coma therapy. In the traditional stair step treatment of intracranial hypertension, barbiturate coma therapy has the most potential capacity to reduce $\mathrm{ICP}^{17)}$. Therefore, many neurosurgeons consider barbiturate coma therapy for the refractory high $\mathrm{ICP}^{16)}$. In the point of limitation of this study, 3-days coma therapies were performed without precise scientific considerations, and further comprehensive studies are needed to confine the duration of therapy and the time of weaning coma therapy.

\section{CONCLUSION}

Barbiturate and propofol coma therapy are known to have similar important neuroprotective roles. However, in spite of the several practical advantages of propofol over barbiturate such as less systemic hypotension during coma therapy and shorter time to stationary state, it is not a completely safe anesthetic agent. The determination of the optimal dose required to maximize its neuroprotective effects and avoid fatal complications is of considerable importance. The findings of the present study suggest that BIS can be used to determine the optimal dose of propofol so as to increase its neuroprotective effects and reduce its side effects during coma therapy.

\section{CONFLICT OF INTEREST}

The authors have no financial conflicts of interest.

\section{ACKNOWLEDGEMENTS}

I thank the following individuals: Young Min Kim, M.D., and Mi-Ok Sunwoo, M.D., (Department of Radiology, Samsung Changwon Hospital) for their review of the neuroradiological images; and Young Wook Kim, M.D., (Department of Biostatistics, Samsung Changwon Hospital) for assistance with the statistical analysis.

\section{REFERENCES}

1. Alali AS, Naimark DM, Wilson JR, Fowler RA, Scales DC, Golan E, et al. Economic evaluation of decompressive craniectomy versus barbiturate coma for refractory intracranial hypertension following traumatic brain injury. Crit Care Med 2014;42:2235-2243.

2. Alnemari AM, Krafcik BM, Mansour TR, Gaudin D. A comparison of pharmacologic therapeutic agents used for the reduction of intracranial pressure after traumatic brain injury. World Neurosurg 2017;106:509-528.

3. Beatrice V, Frank R, Andrea C, Nichola L. The physiology of propofol infusion syndrome; a simple name for a complex syndrome. Intensive Care Med 2003;29:1417- 1425.

4. Bhargava AK, Setlur R. Correlation of bispectral index and Guedel's stages of ether anesthesia. Anesth Analg 2004;98:132-124.

5. Cremer OL, Moons KGM, Bouman EAC, Kruijiswijk JE, de Smet AM, Kalman CJ. Long-term propofol infusion and cardiac failure in adult head-injured patients. Lancet 2001;357:117-118.

6. Czosnyka M, Steiner L, Balestreri M, Schmidt E, Smielewski P, Hutchinson PJ, et al. Concept of "true ICP" in monitoring and prognostication in head trauma. Acta Neurochir Suppl 2005;95:341-344.

7. Hatch DJ. Propofol infusion syndrome in children. Lancet 1999;353:1117-1118.

8. Ishii H, Arai T, Segawa H, Morikawa S, Inubushi T, Kukuda $\mathrm{K}$. Effects of propofol on lactate and edema formation in focal cerebral ischemia in hyperglycemic rats. British J Anesth 2002;88:412-417.

9. Jacobi J, Fraser GL, Coursion DB, Riker RR, Fontain D, Wittbrodt ET, et al. Clinical practice guidelines for the sustained use of sedatives and analgesics in the critically ill adult. Crit Care Med 2002;30:119-141.

10. Jay WJ, Peter SS. Development and clinical application of electroencephalographic bispectrum monitoring. Anesthesiology 2000;93:1336-1344.

11. Kochs E, Hoffman WE, Werner C, Thomas C, Albrecht RF, 
Shulte am Esh J. The effects of propofol on brain electrical activity, neurologic outcome, and neuronal damage following incomplete ischemia in rats. Anesthesiology 1992;76:245252.

12. Lee JW, Woo JH, Baik HJ, Kim DY, Chae JS, Yang NR, et al. The effect of anesthetic agents on cerebral vasospasms after subarachnoid hemorrhage: a retrospective study. Medicine (Baltimore) 2018;97:e11666.

13. Levy ML, Rabb C, Couldwell WT, Zelman V, Apuzzo MLJ. Protection of the neural pool. In: Apuzzo MLJ, editor. Brain Surgery: Complication avoidance and management. New York: Churchill Livingston; 1993. p. 857-889.

14. Martin R, Ivan J, Marek M, Ingrid W, Walter M. Severe traumatic brain injury in Austria VI; Effects of guideline-based management. Wien Klin Wochenschr 2007;119:64-71.

15. Michenfielder JF, Theye RA. The effects of anesthesia and hypothermia on canine cerebral ATP and lactate during anoxia produced by decapitation. Anesthesiology 1970;33:430-439.

16. Nilsson P, Enbald P, Chamber I, Citerio G, Fiddes H, Howells $\mathrm{T}$, et al. Survey of traumatic brain injury management in European Brain-IT centers year 2001. Acta Neurochir Suppl 2005;95:51-53.

17. Robertson C. Critical care management of traumatic brain injury. In: Winn HR, editor. Youmans Neurosurgical Surgery. 5th ed. Philadelphia: W.B. Saunders; 2004. 5:p. 5103-5144.

18. Skoutelis A, Lianou P, Papageorgious E, Kokkinis K, Alexopolous K, Bassaris H. Effects of propofol and thiopentone on polymorphonuclear leukocyte functions in vitro. Acta Anesthsiol Scand 1994;38:858-862.

19. Smith DS, Rehncrona S. Siesjo BK. Barbiturates as protective agents in brain ischemia and as free radical scavengers in vitro. Acta Physiol Scand Suppl 1980;492:129-134.

20. Spetzler RF, Hadley MN. Protection against cerebral ischemia; the role of barbiturates. Cerebrovasc Brain Metab Rev 1989;1:212-229.

21. Steen PA, Michenfielder JD. Cerebral protection with barbiturate; relation to anesthetic effect. Stroke 1978;9:140142.

22. Steen PA, Michenfeilder JD. Mechanisms of barbiturate protection. Anesthesiology 1980;53:183-185.

23. Teichberg VI, Tal N, Goldberg O, Luini A. Barbiturates, alcohols and the CNS excitatory neurotransmission; specific effects on the kainite and quisqualate receptors. Brain Res 1984;291:285-292.

24. Zarchin N, Guggenheimer-Furman E, Meilin S, Ornstein E, Mayevsky A. Thiopental induced cerebral protection during ischemia in gerbilis. Brain Res 1998;780:230-236. 